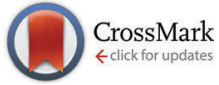

Cite this: Phys. Chem. Chem. Phys., 2015, 17, 12310

Received 17th February 2015 Accepted 9th April 2015

DOI: $10.1039 / \mathrm{c} 5 \mathrm{cp} 01009 \mathrm{~h}$

www.rsc.org/pccp

\section{Photoinduced molecular dissociation and photoinduced recombination mediated by superfluid helium nanodroplets}

\author{
Andreas Kautsch, Markus Koch* and Wolfgang E. Ernst*
}

We have investigated photoinduced chemical reaction dynamics of cold, isolated $\mathrm{Cr}_{2}$ molecules in helium nanodroplets $\left(\mathrm{He}_{\mathrm{N}}\right)$, exploiting the quantum state specific spatial separation of solvated and surface locations on the droplet. The molecules are excited to achieve dissociation to a ground state $\left(a^{7} S_{3}\right)$ and a metastable state $\left(a^{5} S_{2}\right)$ atom. State specific spatial separation, in combination with efficient translational cooling to avoid ejection, causes the ground state atom to be solvated inside the droplet while the metastable atom migrates to the surface. A barrier between the two reactants formed by the $\mathrm{He}_{\mathrm{N}}$ prevents recombination. We apply a resonance-enhanced multiphoton ionization scheme including the $\mathrm{y}^{5} \mathrm{P}_{1,2,3}^{\circ} \leftarrow \mathrm{a}^{5} \mathrm{~S}_{2}$ transition of the surface atom as well as a two-laser scheme including the $\mathrm{y}^{7} \mathrm{P}_{2,3,4}^{\circ} \leftarrow \mathrm{a}^{7} \mathrm{~S}_{3}$ transition of the solvated atom in order to verify the locations and separation of the dissociation products. Furthermore, ionization of the $a^{5} \mathrm{~S}_{2}$ surface atom triggers solvation followed by geminate recombination with the $a^{7} S_{3}$ atom, which is verified by the detection of $\mathrm{Cr}_{2}{ }^{+}$molecular ions. For small $\mathrm{Cr}$ clusters, our results indicate that they may be composed of chromium dimers that exhibit the same dissociation behavior.

\section{Introduction}

Helium nanodroplets $\left(\mathrm{He}_{\mathrm{N}}\right)$ represent a well-established matrix for the spectroscopic investigation of isolated, cold $(0.4 \mathrm{~K})$ atoms, molecules, and clusters ${ }^{1}$ and offer a unique method for cold chemistry on a single molecule level. The spatial separation of surface located and solvated dopants in $\mathrm{He}_{\mathrm{N}}$ provides a promising approach to control and monitor chemical reactions, especially if the location is state specific and can thus be changed by photoexcitation. In this article we demonstrate a complete cycle of photoinduced molecular dissociation, spatial separation of the fragments to a fully solvated and a stable, surface bound state and finally, photoinduced geminate recombination of the fragments.

Increasing interest in exploring chemical reactions in $\mathrm{He}_{\mathrm{N}}$ originates from the ability to stabilize and investigate radical reaction intermediates ${ }^{2-7}$ or confine dissociation fragments to the volume of the droplet. ${ }^{8,9}$ High cooling rates permit efficient relaxation of excited molecules, ${ }^{1,8}$ the formation and stabilization of metastable clusters, ${ }^{10,11}$ or aggregation of weak van der Waals bound complexes (see, e.g., ref. 12). Shallow energy barriers along reaction pathways can lead to trapping in local reactive potentialenergy surface minima ${ }^{4}$ which can be overcome by photo-activation

Graz University of Technology, Institute of Experimental Physics, NAWI Graz, Petersgasse 16, A-8010 Graz, Austria.E-mail: markus.koch@tugraz.at, wolfgang.ernst@tugraz.at to trigger chemical reactions. ${ }^{13,14}$ The location of a dopant is dictated by the interaction with helium (the pair potential) and can be estimated by the dimensionless Ancilotto parameter. ${ }^{15}$ While the majority of atoms and molecules in their ground state are located inside the droplet, an electronic transition from the ground state to an excited state can initiate migration from inside to the droplet surface. This has been observed, for example, for $\mathrm{Ag},{ }^{16-18} \mathrm{Cu},{ }^{19,20} \mathrm{Cr},{ }^{21-23} \mathrm{CF}_{3},{ }^{24,25}$ and NO. ${ }^{26}$ Usually, surface migration is followed by desorption from the droplet, only for $\mathrm{NO}^{*}$ there was indication that the excited molecule remains in a surfacebound state. ${ }^{26}$ For droplets doped with both surface located and solvated species the helium matrix can form a barrier that prevents molecule formation or clustering, even in the presence of long range van der Waals interaction. ${ }^{27}$ On the other side, van der Waals forces between solvated noble gas atoms and surface-located alkaline earth metal atoms can be exploited to overcome the separating character of $\mathrm{He}_{\mathrm{N}} \cdot{ }^{28,29}$ Transition from a surface location to solvation was achieved for the $\mathrm{HCN}-\mathrm{Sr}$ complex (and vice versa for $\mathrm{HCN}-\mathrm{Ca}$ ) by vibrational excitation, ${ }^{30}$ and in general, surfacelocated species migrate inside the droplet upon ionization. ${ }^{31-34}$

Here we demonstrate that photoexcitation of solvated $\mathrm{Cr}_{2}$ molecules results in dissociation to one atom in a solvated state $\left(a^{7} S_{3}\right)$ and a second atom in a surface bound state $\left(a^{5} S_{2}\right)$. Both fragments are sufficiently cooled to prevent ejection from the droplet. A resonant three photon ionization scheme is applied to the surface atom to verify its location and, at the same time, trigger solvation and recombination with its original partner. 
The stable interior location of the other fragment is proven with a two laser experiment, where both lasers are scanned individually.

\section{Experimental}

Chromium clusters $\left(\mathrm{Cr}_{2}-\mathrm{Cr}_{4}\right)$ are formed inside helium nanodroplets by the pickup of single $\mathrm{Cr}$ atoms. The setup follows a Helium Nanodroplet Isolation (HENDI) apparatus, described in detail in ref. 35 . In brief, $\mathrm{He}_{\mathrm{N}}$ are formed by the supersonic expansion of high purity ${ }^{4} \mathrm{He}$ gas through a cooled nozzle (diameter $d=5 \mu \mathrm{m}$, stagnation pressure $p_{0}=50 \mathrm{bar}$ ). Droplet sizes follow a log-normal distribution with a distribution maximum of $\hat{N}=6300$ He atoms (mean droplet size $\bar{N}=16000$ ) for a nozzle temperature of $14 \mathrm{~K}$. The collimated $\mathrm{He}_{\mathrm{N}}$ beam is crossed at right angles by an effusive beam of $\mathrm{Cr}$ atoms from an electron bombardment $\mathrm{Cr}$ oven ${ }^{36}$ beneath the $\mathrm{He}_{\mathrm{N}}$ beam. This setup ensures that no free atoms reach the detection region. To characterize the pick-up conditions, the number of $\mathrm{Cr}_{1,2, \ldots}{ }^{+}$ions formed by electron bombardment ionization is monitored as function of the oven heating power. A quadrupole mass spectrometer (QMS, Balzers QMG 422) is attached at the end of the measurement chamber to facilitate mass selective ion detection. This allows an assignment of the photoion signal to a specific $\mathrm{Cr}_{n}$ cluster size, by comparing the photoion yield to the electron bombardment $\mathrm{Cr}_{1,2, \ldots}{ }^{+}$yield as a function of heating power.

Excitation spectra of the $\mathrm{Cr}_{n}-\mathrm{He}_{\mathrm{N}}(n=2-4)$ complexes are recorded with resonance-enhanced multiphoton ionization (REMPI) spectroscopy. ${ }^{21}$ Laser pulses are obtained from excimer (XeCl, Radiant Dyes RD-EXC-200, 308 nm, 20 ns pulse duration) pumped dye lasers. For one-color REMPI, a pulsed dye laser beam (Lamda Physik, FL3002, dyes: Coumarin 2, Coumarin 102) intersects the doped $\mathrm{He}_{\mathrm{N}}$ beam at right angles in the extraction region of the QMS. The mass window of the QMS is set to integrate the signal of the $\mathrm{Cr}_{n}{ }^{+}$isotopes and $\mathrm{Cr}_{n}{ }^{+}-\mathrm{He}$ around the central cluster mass to increase the signal. To further increase the signal quality, two-color REMPI is used in addition. ${ }^{23}$ Therefore, a fraction of the $308 \mathrm{~nm}$ pump laser light is overlapped with the dye laser.

A pump-probe scheme is applied to observe the formation of ground state atoms after dissociating $\mathrm{Cr}_{2}$. Two dye laser beams (Radiant Dyes, DL-midi, dye: Coumarin 2; Lamda Physik, FL3002, dye: RDC360 neu) intersect the doped $\mathrm{He}_{\mathrm{N}}$ beam, where the first one dissociates the molecules, while the second ionizes the produced ground state $\mathrm{Cr}$ atoms state selectively with a known REMPI scheme. ${ }^{21}$ In addition to the signal from dissociated $\mathrm{Cr}_{2}$, single $\mathrm{Cr}$ atom doped $\mathrm{He}_{\mathrm{N}}$ cause a background signal, which is subtracted by a difference detection scheme (dissociation laser on minus off). The fluence of the dissociation laser is kept low in order to prevent ionization of the dissociation products (in contrast to the experiment described above).

In Fig. 1 the $\mathrm{Cr}_{2}$ potential energy curves ${ }^{37,38}$ and $\mathrm{Cr}$ atom energy levels ${ }^{39}$ that are of relevance for the presented experiments

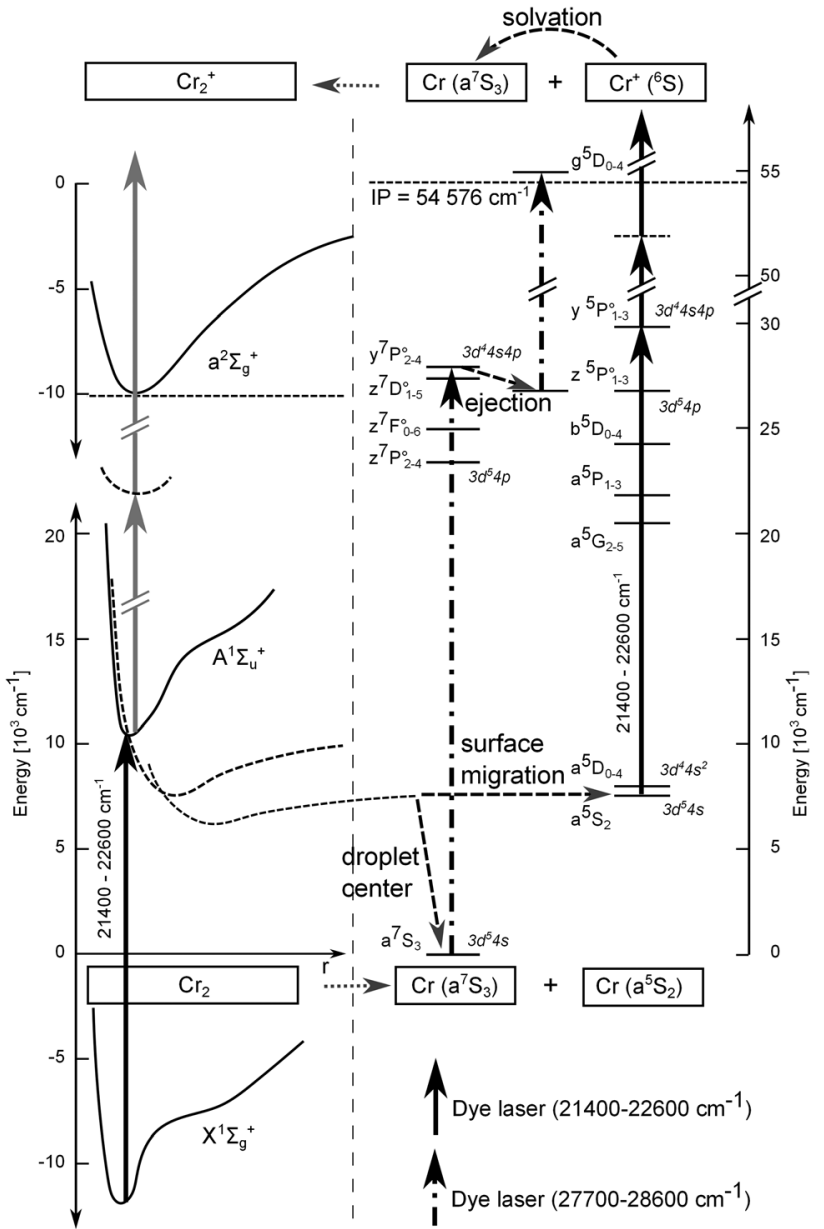

Fig. $1 \mathrm{Cr}_{2}$ and $\mathrm{Cr}_{2}{ }^{+}$potential energy curves ${ }^{37,38}$ (left) and $\mathrm{Cr}$ atom energy levels ${ }^{39}$ (right). A one-color ionization scheme is indicated by a combination of solid arrows (laser excitation) and dashed arrows (relaxation). Upon $\mathrm{Cr}_{2}$ excitation to the $\mathrm{A}^{1} \Sigma_{\mathrm{u}}{ }^{+}$state inside $\mathrm{He}_{\mathrm{N}}$, the molecule undergoes relaxation to predissociating states resulting in $a^{7} S_{3} \mathrm{Cr}$ and $a^{5} \mathrm{~S}_{2} \mathrm{Cr}$ atom states. While the first remains solvated inside the droplet, the latter migrates to the surface where it is ionized by a resonant three photon scheme. This triggers solvation and recombination to $\mathrm{Cr}_{2}{ }^{+}$(top of the figure). The ionization path to probe the ground state atom with a second dye laser is indicated by dash-dotted arrows. ${ }^{21} \mathrm{~A}$ suggested ionization path that does not include $\mathrm{Cr}_{2}$ dissociation is indicated by gray arrows.

are shown, together with an excitation-ionization scheme indicated with arrows. The first step in this scheme is excitation of ground state $\mathrm{Cr}_{2}\left(4 \sigma^{2} 3 \mathrm{~d} \sigma^{2} 3 \mathrm{~d} \pi^{4} 3 \mathrm{~d} \delta^{440}\right)$ inside $\mathrm{He}_{\mathrm{N}}$ via the $\mathrm{A}^{1} \Sigma_{\mathrm{u}}{ }^{+} \leftarrow \mathrm{X}^{1} \Sigma_{\mathrm{g}}{ }^{+}$ transition. The excited $\mathrm{A}^{1} \Sigma_{\mathrm{u}}{ }^{+}$state correlates to one ground state $\left(\mathrm{a}^{7} \mathrm{~S}_{3}, 3 \mathrm{~d}^{5} 4 \mathrm{~s}\right)$ and one excited $\left(\mathrm{z}^{7} \mathrm{P}^{\circ}, 3 \mathrm{~d}^{5} 4 \mathrm{p}\right) \mathrm{Cr}$ atom, and, as will be shown below, dissociates via internal conversion to form one $a^{7} S_{3}$ and one $\mathrm{a}^{5} \mathrm{~S}_{2}\left(3 \mathrm{~d}^{5} 4 \mathrm{~s}\right)$ atom.

\section{Results}

One-color REMPI excitation spectra of $\mathrm{Cr}_{2}$ via the $\mathrm{A}^{1} \Sigma_{\mathrm{u}}{ }^{+} \leftarrow \mathrm{X}^{1} \Sigma_{\mathrm{g}}{ }^{+}$ transition for $\mathrm{Cr}^{+}$and $\mathrm{Cr}_{2}{ }^{+}$detection are shown in Fig. 2(a). The broad band, stretching from 21500 to $22750 \mathrm{~cm}^{-1}$, is attributed to the $\mathrm{Cr}_{2} \mathrm{~A}^{1} \Sigma_{\mathrm{u}}{ }^{+} \leftarrow \mathrm{X}^{1} \Sigma_{\mathrm{g}}{ }^{+}$transition and the three pronounced 


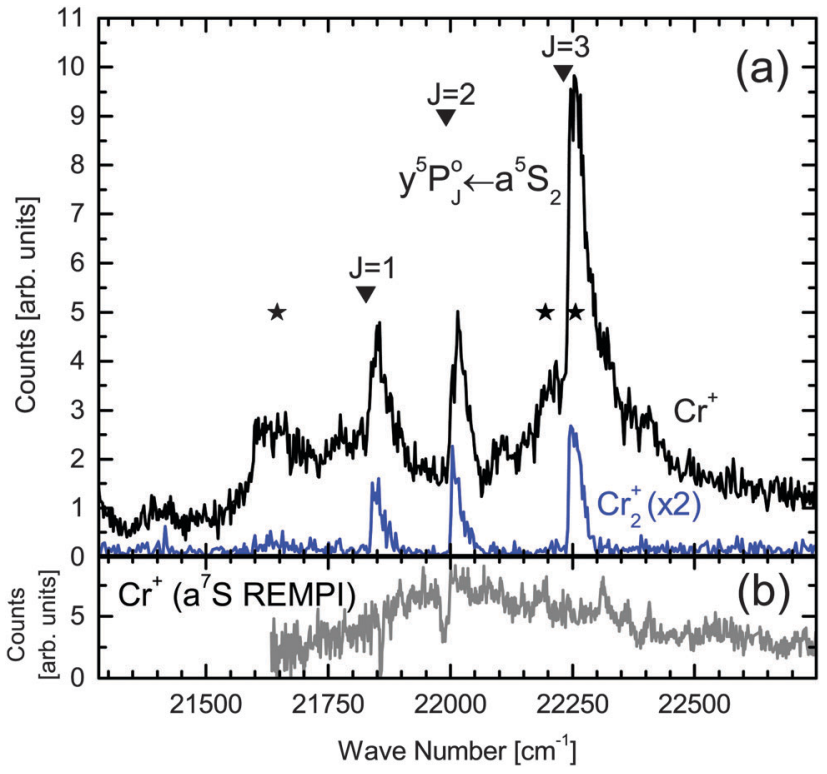

Fig. 2 (a) One-color REMPI spectra in the range of the $\mathrm{Cr}_{2} \mathrm{~A}^{1} \Sigma_{\mathrm{u}}{ }^{+} \leftarrow \mathrm{X}^{1} \Sigma_{\mathrm{g}}{ }^{+}$ transition. Photoions are detected at the mass of $\mathrm{Cr}^{+}$(black line) and $\mathrm{Cr}_{2}{ }^{+}$ (blue line, multiplied by 2). The bare $\mathrm{Cr}$ atom $\mathrm{y}^{5} \mathrm{P}_{1,2,3}^{0} \leftarrow \mathrm{a}^{5} \mathrm{~S}_{2}$ transition energies are indicated with triangles. ${ }^{39}$ Asterisks mark the wavelengths at which the photoion yield is compared to the $\mathrm{Cr}_{1,2, \ldots}{ }^{+}$ion yield obtained with electron impact ionization in dependence on the pick-up oven temperature. (b) Excitation spectrum in the range of the $\mathrm{Cr}_{2} \mathrm{~A}^{1} \Sigma_{\mathrm{u}}{ }^{+} \leftarrow$ $X^{1} \Sigma_{g}{ }^{+}$transition, recorded with a pump-probe laser scheme. The dissociating laser is scanned across the $\mathrm{Cr}_{2}$ band, while the second laser ionizes the produced ground state atoms with $a^{7} \mathrm{~S}$ REMPI (includes the $\mathrm{y}^{7} \mathrm{P}_{2,3,4}^{0} \leftarrow$ $\mathrm{a}^{7} \mathrm{~S}_{3}$ transition). Narrow dips and peaks are artifacts due to experimental instabilities.

peaks can be assigned to $\mathrm{Cr}$ atom $\mathrm{y}^{5} \mathrm{P}_{1,2,3}^{0} \leftarrow \mathrm{a}^{5} \mathrm{~S}_{2}$ transitions (indicated by triangles ${ }^{39}$ ). Because the $\mathrm{A}^{1} \Sigma_{\mathrm{u}}{ }^{+} \leftarrow \mathrm{X}^{1} \Sigma_{\mathrm{g}}{ }^{+}$molecular band overlaps with the atomic transition energies, these peaks indicate the photoinduced dissociation with one of the fragments being in the $\mathrm{a}^{5} \mathrm{~S}_{2}$ state, as will be discussed in detail below. The whole excitation-ionization process from $a^{5} S_{2}$ is indicated with solid, upwards pointing arrows in Fig. $1 . \mathrm{Cr}_{2}$ is excited to a predissociating state that leads to the formation of a ground state $\mathrm{a}^{7} \mathrm{~S}_{3}$ and a metastable state $\mathrm{a}^{5} \mathrm{~S}_{2}$ atom. ${ }^{41}$ The latter is excited via the $\mathrm{y}^{5} \mathrm{P}_{1,2,3}^{0} \leftarrow \mathrm{a}^{5} \mathrm{~S}_{2}$ transition and ionized with either two (one-color REMPI) or one (two-color REMPI) photon. This ionization path selectively addresses $\mathrm{a}^{5} \mathrm{~S}_{2}$ metastable $\mathrm{Cr}$ atoms and will be called $\mathrm{a}^{5} \mathrm{~S}$ REMPI from now on. For further insight into the dynamics after dissociation, we present detailed scans across the $y^{5} \mathrm{P}_{3}^{0} \leftarrow \mathrm{a}^{5} \mathrm{~S}_{2}$ transition for the detection of $\mathrm{Cr}^{+}$to $\mathrm{Cr}_{4}{ }^{+}$in Fig. 3. Although one-color and two-color REMPI give equal results, the latter provides a better signal to noise ratio and was thus chosen. One $308 \mathrm{~nm}$ photon is used for ionization of excited $\mathrm{y}^{5} \mathrm{P}_{3}^{\circ}$ state atoms instead of two dye laser photons (cf. Fig. 1). The spectral signature is similar for detection of $\mathrm{Cr}_{1,2,3,4}{ }^{+}$, where the appearance of $\mathrm{Cr}_{3,4}{ }^{+}$is connected to larger $\mathrm{Cr}_{n}(n=3,4, \ldots)$ clusters, as will be discussed in Section 4.3.

While the production of the metastable $\mathrm{a}^{5} \mathrm{~S}_{2}$ atom as one of the dissociation products is verified with $a^{5} \mathrm{~S}$ REMPI

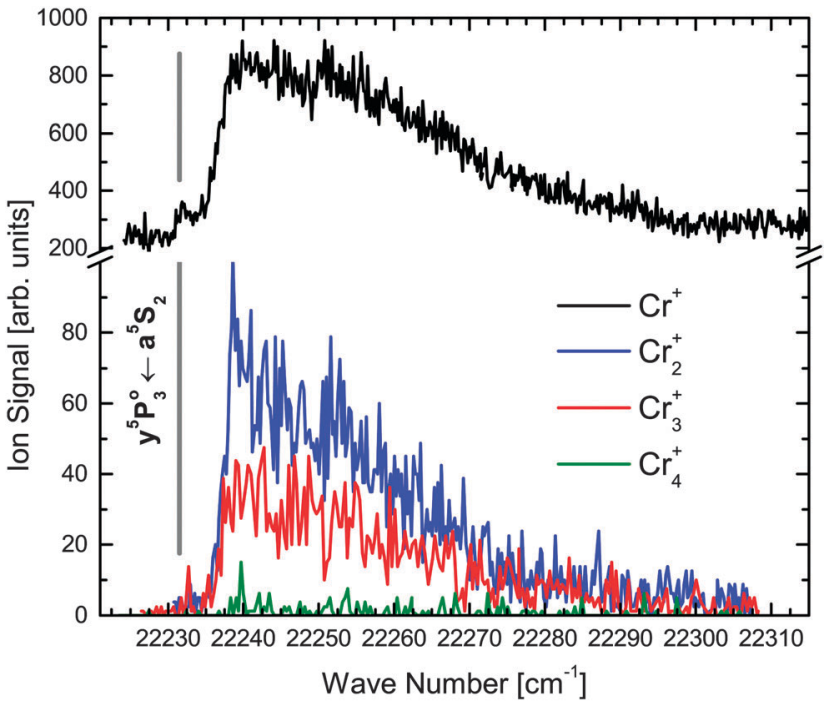

Fig. 3 High resolution REMPI scan of the $y^{5} \mathrm{P}_{3}^{0} \leftarrow \mathrm{a}^{5} \mathrm{~S}_{2}$ transition within the $\mathrm{Cr}_{2} \mathrm{~A}^{1} \Sigma_{\mathrm{u}}{ }^{+} \leftarrow X^{1} \Sigma_{\mathrm{g}}{ }^{+}$band (Fig. 2) for detection of $\mathrm{Cr}_{1,2,3,4}{ }^{+}$ions (two-color ionization scheme with the $\mathrm{XeCl}$ laser at $308 \mathrm{~nm}$ as second wavelength). The bare $\mathrm{Cr}$ atom $\mathrm{y}^{5} \mathrm{P}_{3}^{0} \leftarrow \mathrm{a}^{5} \mathrm{~S}_{2}$ transition energy is indicated with a vertical line. ${ }^{39}$

(see Fig. 2(a) and 3), the verification of the other dissociation product - the $\mathrm{a}^{7} \mathrm{~S}_{3}$ ground state atom - requires a second laser. It ionizes the $\mathrm{a}^{7} \mathrm{~S}_{3}$ atom with a well known $\mathrm{Cr}$ one-color REMPI scheme ${ }^{21}$ that includes the $\mathrm{y}^{7} \mathrm{P}_{2,3,4}^{\circ} \leftarrow \mathrm{a}^{7} \mathrm{~S}_{3}$ ground state transition (Fig. 1, dash-dotted arrows) and is called $\mathrm{a}^{7} \mathrm{~S}$ REMPI from now on. The two-laser scheme opens the possibility to scan both laser wavelengths individually. First, the dissociation process is studied (Fig. 2(b)) by scanning the dissociation laser across the $\mathrm{Cr}_{2}$ excitation band and photoionizing the produced ground state atoms with $\mathrm{a}^{7} \mathrm{~S}$ REMPI $(\bar{\nu}=$ $28204 \mathrm{~cm}^{-1}$ ). Note that a certain fraction of the $\mathrm{He}_{\mathrm{N}}$ are originally doped with single $\mathrm{a}^{7} \mathrm{~S}_{3} \mathrm{Cr}$ atoms according to the pick-up statistics. Hence, for all two dye laser experiments a differential measurement is applied to subtract these atoms from the $\mathrm{Cr}_{2}$ dissociation signal.

To gain information about the location of the $\mathrm{a}^{7} \mathrm{~S}_{3} \mathrm{Cr}$ atom, the dissociating laser wavelength is kept constant at $\bar{\nu}=$ $21978 \mathrm{~cm}^{-1}$ and the $\mathrm{a}^{7} \mathrm{~S}$ laser is scanned across the atomic $\mathrm{y}^{7} \mathrm{P}_{2,3,4}^{\circ} \leftarrow \mathrm{a}^{7} \mathrm{~S}_{3}$ ground state transition. It was shown for single $\mathrm{Cr}$ atoms solvated inside $\mathrm{He}_{\mathrm{N}}$, that the $\mathrm{y}^{7} \mathrm{P}_{2,3,4}^{0} \leftarrow \mathrm{a}^{7} \mathrm{~S}_{3}$ ground state transition is shifted and broadened by about 400 to $600 \mathrm{~cm}^{-1}$ due to the Pauli repulsion of the surrounding helium. ${ }^{21-23}$ As indicated in Fig. 1, after excitation to $\mathrm{y}^{7} \mathrm{P}_{2,3,4}^{\circ}$ the atoms are ejected from the droplet while relaxing to energetically lower states $\left(\right.$ e.g., $\left.\mathrm{z}^{5} \mathrm{P}_{1,2,3}^{0}\right){ }^{21-23}$ This mechanism enables a highly efficient ionization of bare atoms with one further laser photon, also through $\mathrm{Cr}$ autoionizing states that lie close to the ionization potential $\left(g^{5} \mathrm{D}, \mathrm{e}^{3} \mathrm{D}\right)$. The spectrum with the fixed dissociating laser and the $a^{7}$ S REMPI laser scanning across the ground state transition is shown in Fig. 4(a). Due to a difference scheme, the spectrum can be allocated to $\mathrm{Cr}$ atoms from dissociated $\mathrm{Cr}_{2}$, detected at the $\mathrm{Cr}^{+}$ 

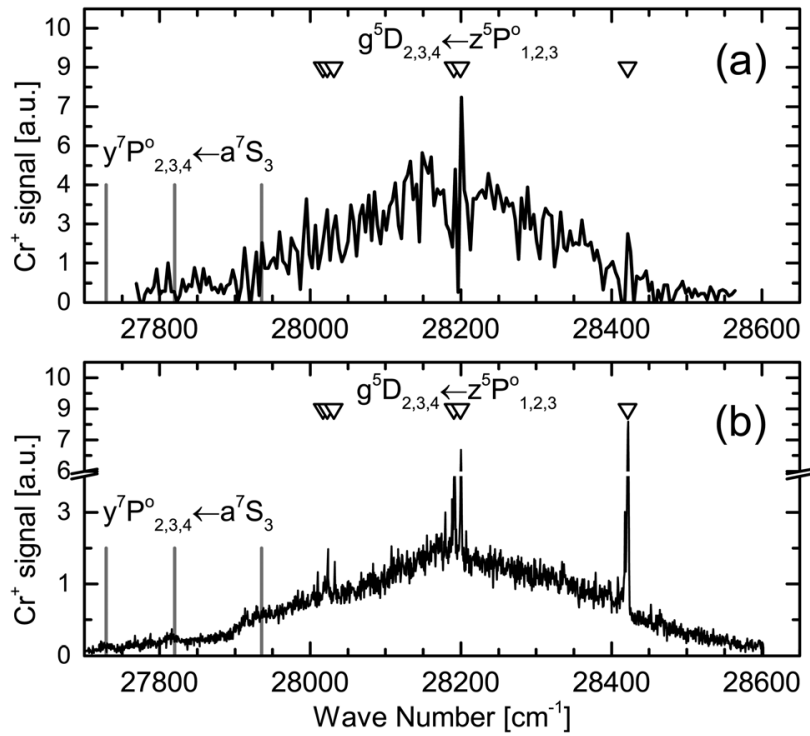

Fig. $4 a^{7} S_{3} R E M P I$ spectra of ground state $C r$ atoms in $\mathrm{He}_{N}$. (a) Spectrum recorded in a two laser experiment, where the $\mathrm{Cr}_{2}$ dissociation laser is fixed $\left(\bar{\nu}=21978 \mathrm{~cm}^{-1}\right)$ and the second laser $\left(a^{7} S_{3}\right.$ REMPI) is scanned. A difference scheme (dissociation laser on minus off) was applied. (b) $a^{7} S_{3}$ REMPI spectrum for single $\mathrm{Cr}$-atom doped $\mathrm{He}_{\mathrm{N}}{ }^{21}$ The bare $\mathrm{Cr}$ atom ground state transitions $\mathrm{y}^{7} \mathrm{P}_{2,3,4}^{0} \leftarrow \mathrm{a}^{7} \mathrm{~S}_{3}$ are indicated as vertical lines and transitions to autoionizing states with triangles.

mass. For comparison, the spectrum obtained with $a^{7} \mathrm{~S}$ REMPI of single $\mathrm{Cr}$ atoms in $\mathrm{He}_{\mathrm{N}}$ (not via dissociation of $\mathrm{Cr}_{2}$ ) is plotted in Fig. 4(b) (from ref. 21). In both spectra, the broad structure is attributed to the in-droplet $\mathrm{y}^{7} \mathrm{P}_{2,3,4}^{0} \leftarrow \mathrm{a}^{7} \mathrm{~S}_{3}$ ground state excitation, which is very similar regarding shape and position. The narrow peaks (indicated with triangles) are allocated to the bare atom $\mathrm{g}^{5} \mathrm{D}_{2,3,4} \leftarrow \mathrm{z}^{5} \mathrm{P}_{1,2,3}^{\circ}$ autoionizing transitions. The experimental conditions, i.e. droplet size, for the spectrum in Fig. 4(a) are optimized for $\mathrm{Cr}_{2}$ formation resulting in a lower signal to noise ratio and reduced autoionizing peaks. ${ }^{23}$ A very similar spectrum to Fig. 4(a) was obtained when delaying the $\mathrm{a}^{7} \mathrm{~S}$ REMPI probe laser pulse by $20 \mathrm{~ns}$ with respect to the dissociating pump laser pulse, so that there is no temporal overlap between the pulses.

\section{Discussion}

\subsection{Predissociation}

Photoinduced dissociation in $\mathrm{He}_{\mathrm{N}}$ has been observed for various species. ${ }^{13,25,28,42}$ Predissociation of $\mathrm{Cr}_{2}$ upon excitation to $\mathrm{A}^{1} \Sigma_{\mathrm{u}}{ }^{+}$has been observed in gas phase ${ }^{37,41,43}$ and in matrix. ${ }^{40}$ It was concluded, that the $\mathrm{A}^{1} \Sigma_{\mathrm{u}}{ }^{+}$state is crossed by at least one perturbing state and one predissociating state, where possible assignments were discussed by Andersson. ${ }^{37}$ Riley et $a l^{41}$ propose the nonradiative transition from the $\mathrm{A}^{1} \Sigma_{\mathrm{u}}{ }^{+}$to another bound state. The latter is rapidly dissociated by a state correlating to the separate atom limit states $\mathrm{Cr}\left(\mathrm{a}^{7} \mathrm{~S}_{3}\right)$ and $\mathrm{Cr}\left(\mathrm{a}^{5} \mathrm{~S}_{2}, \mathrm{a}^{5} \mathrm{D}\right) .{ }^{41}$ From the observation of the $\mathrm{y}^{5} \mathrm{P}_{1,2,3}^{\circ} \leftarrow$ $\mathrm{a}^{5} \mathrm{~S}_{2}$ and $\mathrm{y}^{7} \mathrm{P}_{2.3 .4}^{\circ} \leftarrow \mathrm{a}^{7} \mathrm{~S}_{3}$ atomic transitions, we clearly identify the population of the $a^{5} S_{2}$ and $a^{7} S_{3}$ atom states and assign the following dissociative process:

$$
\mathrm{Cr}_{2}\left(\mathrm{X}^{1} \Sigma_{\mathrm{g}}^{+}\right) \stackrel{h \nu}{\longrightarrow} \mathrm{Cr}_{2}\left(\mathrm{~A}^{1} \Sigma_{\mathrm{u}}^{+}\right) \rightarrow \mathrm{Cr}\left(\mathrm{a}^{7} \mathrm{~S}_{3}\right)+\mathrm{Cr}\left(\mathrm{a}^{5} \mathrm{~S}_{2}\right)
$$

\subsection{Separation to a surface located $a^{5} S_{2}$ and a solvated $a^{7} S_{3}$ atom}

The fate after dissociation is dictated by the interaction of the Cr atoms in the respective state $\left(\mathrm{a}^{7} \mathrm{~S}_{3}, \mathrm{a}^{5} \mathrm{~S}_{2}\right)$ with He atoms. ${ }^{44,45}$ In principle, the atoms can remain solvated inside the $\mathrm{He}_{\mathrm{N}}$, stay bound on the surface, or detach from the $\mathrm{He}_{\mathrm{N}}$ with a certain probability to take a few He atoms along. Since the droplet acts as a heat bath, kinetic energy can be dissipated to prevent ejection. ${ }^{8,9}$ An excess energy of about $0.4 \mathrm{eV}\left(3200 \mathrm{~cm}^{-1}\right)$, given by the difference of excitation energy and the dissociation limit (cf. Fig. 1), can be compensated by the evaporation of $640 \mathrm{He}$ atoms. So the location of the dopants after dissociation is governed by the electronic states of the atoms. Experimentally, the location of the two fragments is obtained from the lineshapes of the $\mathrm{a}^{7} \mathrm{~S}$ REMPI (via $\mathrm{y}^{7} \mathrm{P}_{2,3,4}^{0} \leftarrow \mathrm{a}^{7} \mathrm{~S}_{3}$ ) and the $\mathrm{a}^{5} \mathrm{~S}$ REMPI (via $\mathrm{y}^{5} \mathrm{P}_{1,2,3}^{\circ} \leftarrow \mathrm{a}^{5} \mathrm{~S}_{2}$ ) spectra. As observed for single $\mathrm{Cr}$ atoms in earlier experiments ${ }^{21-23}$ and as predicted by theoretical studies, ${ }^{44,45}$ the ground state $\left(\mathrm{a}^{7} \mathrm{~S}_{3}\right)$ atom remains solvated inside the droplet. The metastable state $\left(\mathrm{a}^{5} \mathrm{~S}_{2}\right)$ atom, in contrast, favors a surface location, which is suggested by DFT calculations (ref. 45) and is supported by the experimental observations, as follows.

We start with the $\mathrm{a}^{5} \mathrm{~S}_{2}$ atom, because the in-droplet $\mathrm{A}^{1} \Sigma_{\mathrm{u}}{ }^{+} \leftarrow$ $\mathrm{X}^{1} \Sigma_{\mathrm{g}}^{+}$molecule band overlaps in energy with the atom $\mathrm{y}^{5} \mathrm{P}_{1,2,3}^{\circ} \leftarrow \mathrm{a}^{5} \mathrm{~S}_{2}$ transition, leading to excited $\mathrm{Cr}^{*}\left(\mathrm{y}^{5} \mathrm{P}^{\circ}\right)$ atoms which are photoionized by absorption of two photons (Fig. 1), so that $\mathrm{Cr}^{+}$ions are detected upon detachment from the droplet. In the $\mathrm{Cr}^{+}$signal in Fig. 2(a), all three peaks of the $\mathrm{y}^{5} \mathrm{P}_{1,2,3}^{\circ} \leftarrow \mathrm{a}^{5} \mathrm{~S}_{2}$ transition are observable. Considering the detailed $\mathrm{Cr}^{+}$scan (Fig. 3) of the most intense $\mathrm{y}^{5} \mathrm{P}_{3}^{\circ} \leftarrow \mathrm{a}^{5} \mathrm{~S}_{2}$ peak, the onset of the main feature is shifted approximately $5 \mathrm{~cm}^{-1}$ to the blue relative to the bare atom transition energy. A maximum is reached at $22240 \mathrm{~cm}^{-1}$ followed by an almost steady signal decrease, giving a total peak width of $\sim 50 \mathrm{~cm}^{-1}$. These spectral characteristics are comparable to transitions of heavier alkali metal atoms that reside in a surface dimple, ${ }^{27,35,46}$ which is a first indication for the surface location of the $a^{5} S_{2}$ atom (others will follow). At the bare atom transition energy (indicated with a vertical line in the detailed scan in Fig. 3), the absence of sharp atomic lines proves that hardly any atoms are ejected from the droplet upon dissociation, encouraging the interpretation in terms of the effective kinetic energy dissipation upon predissociation.

We consider it important to mention that the $\operatorname{Cr} \mathrm{y}^{5} \mathrm{P}_{1,2,3}^{\circ} \leftarrow$ $\mathrm{a}^{5} \mathrm{~S}_{2}$ excitation observed here on the $\mathrm{He}_{\mathrm{N}}$ surface is of completely different nature than the $\mathrm{z}^{5} \mathrm{P}^{\circ} \leftarrow \mathrm{a}^{5} \mathrm{~S}_{2}$ excitation of bare $\mathrm{Cr}$ atoms and small $\mathrm{Cr}-\mathrm{He}_{n}(n=1,2, \ldots)$ exciplexes observed in our previous studies. ${ }^{23}$ This becomes obvious by comparing the 
corresponding line shapes. In the two-color REMPI scheme in ref. 23, $308 \mathrm{~nm}$ excitation and droplet mediated relaxation results in bare $\mathrm{a}^{5} \mathrm{~S}_{2} \mathrm{Cr}$ atoms and $\mathrm{Cr}-\mathrm{He}_{n}$ exciplexes, both being ejected from the $\mathrm{He}_{\mathrm{N}}$. The corresponding excitation spectrum is composed of a sharp atom line accompanied by a wing to the blue (due to $\mathrm{Cr}-\mathrm{He}_{n}$ ). Here, in contrast, we find hardly any signal at the bare atom line position (Fig. 3) and observe the onset of the peak $5 \mathrm{~cm}^{-1}$ to the blue. Although the XeCl laser was present for recording the spectra in Fig. 3, a bare atom transition peak is hardly detectable. Systematic studies showed an increased bare atom signal for higher $\mathrm{XeCl}$ laser fluence, which starts causing the ejection process.

We now turn to the location and environment of the other dissociation fragment - the $\mathrm{a}^{7} \mathrm{~S}$ ground state atom - based on the two dye laser experiment. The first laser excites the dissociating $\mathrm{A}^{1} \Sigma_{\mathrm{u}}{ }^{+} \leftarrow \mathrm{X}^{1} \Sigma_{\mathrm{g}}{ }^{+} \mathrm{Cr}_{2}$ transition and the second laser the $a^{7} S$ REMPI. Fig. 4(a) shows the $a^{7} S$ REMPI spectrum, recorded from the dissociation fragment. The fact that $a^{7} S$ atoms are detected by the differential scheme proves the proposed predissociation mechanism. The spectrum is compared to the reference spectrum obtained from single atom doped $\mathrm{He}_{\mathrm{N}}$ (Fig. 4(b)). ${ }^{21}$ The spectral similarity of the broad structure, which represents the in-droplet broadened $\mathrm{y}^{7} \mathrm{P}_{2,3,4}^{0} \leftarrow$ $a^{7} S_{3}$ transition, indicates a well defined separation after dissociation of the ground state atom from the $\mathrm{a}^{5} \mathrm{~S}_{2}$ atom on the surface. If both dissociation fragments resided inside the $\mathrm{He}_{\mathrm{N}}$, one would expect a spectral line shift like it was observed for $\mathrm{Mg}$ atoms $\left(\frac{\Delta \bar{\nu}}{\bar{\nu}} \sim 2 \%\right) \cdot{ }^{47}$ Hence, the spectral similarity of $\mathrm{a}^{7} \mathrm{~S}_{3}$ atoms from dissociated $\mathrm{Cr}_{2}$ and original $\mathrm{a}^{7} \mathrm{~S}_{3}$ atoms is a further indication of the interior location of the ground state fragment and the surface location of the $a^{5} S_{2}$ atom fragment.

To show the stable position of both fragments after dissociation, the probe laser was time-delayed $(\Delta \tau \sim 20 \mathrm{~ns})$ to avoid a temporal overlap between the dissociation pump laser and the ionizing probe laser pulse. The pump-probe delay has no significant influence on the spectrum. Hence, no indication for a recombination or spatial approach between both neutral fragments within the delay time is found. We thus conclude that the $\mathrm{Cr} \mathrm{a}^{5} \mathrm{~S}_{2}$ atom is stable on the $\mathrm{He}_{\mathrm{N}}$ surface, where it is available for further excitation.

It is important to point out that despite the attractive interaction between the center-located ground state and the surface-located metastable state atoms, molecule formation does not occur. This indicates an energy barrier between the two atoms as a result of the confining potential energy curve of the solvated atom and the attractive $\mathrm{Cr}_{2}\left(\mathrm{a}^{7} \mathrm{~S}_{3}-\mathrm{a}^{5} \mathrm{~S}_{2}\right)$ potential energy curve, in a similar way as it was recently calculated for the $\mathrm{Rb}-\mathrm{Xe}$ van der Waals system in a $\mathrm{He}_{500}$ droplet. $^{27}$

\section{3 $\mathrm{Cr}_{2,3,4}{ }^{+}$from $\mathrm{Cr}_{2}$ and small $\mathrm{Cr}_{n}$ cluster}

The characteristic atomic $\mathrm{y}^{5} \mathrm{P}_{1,2,3}^{0} \leftarrow \mathrm{a}^{5} \mathrm{~S}_{2}$ transition peaks are also present in the REMPI spectra employing $\mathrm{Cr}_{2}{ }^{+}$detection (see Fig. 2(a) and 3), with exactly the same position and shape as for $\mathrm{Cr}^{+}$detection. This is very surprising, because the $\mathrm{Cr}$ atom $\mathrm{y}^{5} \mathrm{P}_{1,2,3}^{\circ} \leftarrow \mathrm{a}^{5} \mathrm{~S}_{2}$ transition obviously has to be a step in the ionization process leading from $\mathrm{Cr}_{2}$ to $\mathrm{Cr}_{2}{ }^{+}$. The observation becomes plausible when we build on the results from before, namely that upon $\mathrm{Cr}_{2}$ dissociation the ${ }^{5} \mathrm{~S}_{2}$ atom is residing on the surface while the $a^{7} S_{3}$ atom remains solvated inside the droplet. After resonant ionization of the surface atom with $a^{5} \mathrm{~S}$ REMPI (see Fig. 1), the $\mathrm{Cr}^{+}$ion has a fair chance to be pulled inside the $\mathrm{He}_{\mathrm{N}}{ }^{32,34,45}$ where it recombines with its original partner to form $\mathrm{Cr}_{2}{ }^{+}$. Forming the $\mathrm{Cr}_{2}{ }^{+} \mathrm{a}^{2} \Sigma_{\mathrm{g}}{ }^{+}$ground state $\left(\mathrm{Cr}\left({ }^{7} \mathrm{~S}\right)+\mathrm{Cr}^{+}\left({ }^{6} \mathrm{~S}\right)\right.$, binding energy $\left.=1.30 \mathrm{eV}^{38}\right)$, releases approximately the same amount of energy to the droplet as the initial $\mathrm{Cr}_{2}$ formation, evaporating $\sim 2100 \mathrm{He}$ atoms. A certain fraction of the droplets is now completely evaporated by this energy input which produces detectable, bare $\mathrm{Cr}_{2}{ }^{+}$ions. Remaining $\mathrm{Cr}_{2}{ }^{+}$doped droplets that survived are not detected within the QMS mass window.

To verify $\mathrm{Cr}_{2}$ doped $\mathrm{He}_{\mathrm{N}}$ as the parent species of the $\mathrm{Cr}_{2}^{+}$ions, the $\mathrm{Cr}_{2}{ }^{+}$ion yield was recorded while increasing the $\mathrm{Cr}$ oven temperature, and hence, the probability distribution for the for-

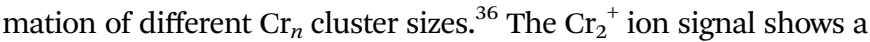
clear dependence on the pick-up oven temperature. For reference, the number of $\mathrm{Cr}_{1,2,3, \ldots}{ }^{+}$ions obtained with electron impact ionization of the doped $\mathrm{He}_{\mathrm{N}}$, is also recorded in dependence on the pick-up oven temperature. Keeping possible fragmentation in mind, the comparison allows an assignment of the $\mathrm{Cr}_{2}^{+} \mathrm{y}^{5} \mathrm{P}_{3}^{\circ} \leftarrow$ $\mathrm{a}^{5} \mathrm{~S}_{2}$ signal (Fig. 2(a), blue line, $22257 \mathrm{~cm}^{-1}$ ) to $\mathrm{Cr}_{2}$ doped $\mathrm{He}_{\mathrm{N}}$.

We mention that in addition to the $\mathrm{Cr}+\mathrm{Cr}^{+} \rightarrow \mathrm{Cr}_{2}^{+}$ recombination, another recombination path is possible, although unlikely. According to DFT calculations, ${ }^{45} \mathrm{Cr}^{*} \mathrm{y}^{5} \mathrm{P}^{\circ}$ atoms have a stable position on the surface and inside the $\mathrm{He}_{\mathrm{N}}$, with a small energy barrier in between. Hence, the $\mathrm{Cr}^{*}\left(\mathrm{y}^{5} \mathrm{P}^{\circ}\right)$ atom might move back inside the droplet to form an excited $\mathrm{Cr}_{2}$ molecule with the $\mathrm{Cr}\left(\mathrm{a}^{7} \mathrm{~S}_{3}\right)$ ground state atom. As above, evaporation of a certain fraction of the droplets and subsequent two photon ionization would lead to $\mathrm{Cr}_{2}{ }^{+}$detection. Irrespective of the recombination path, the recombination process is restricted to the volume of the droplet. The $\mathrm{Cr}_{2}{ }^{+}$detection after $a^{5} S$ REMPI proves the location of both dissociation fragments to be on the droplet.

Now we consider $\mathrm{He}_{\mathrm{N}}$ doped with $\mathrm{Cr}_{3,4}$ clusters. Fig. 3 shows that at the Cr atom $\mathrm{y}^{5} \mathrm{P}_{3}^{\circ} \leftarrow \mathrm{a}^{5} \mathrm{~S}_{2}$ transition also $\mathrm{Cr}_{3}{ }^{+}$and $\mathrm{Cr}_{4}{ }^{+}$ ion clusters are detected. This means, $\mathrm{He}_{\mathrm{N}}$ doped with $\mathrm{Cr}_{3}$ and $\mathrm{Cr}_{4}$ (probably also $\mathrm{Cr}_{5}, \ldots$ ) clusters can undergo a similar excitation process as $\mathrm{Cr}_{2}$, including the characteristic $\mathrm{a}^{5} \mathrm{~S}$ REMPI of a surface located atom and subsequent recombination with the solvated fragments. Because of the strong $\mathrm{Cr}_{2}$ bonding nature, $\mathrm{Cr}_{3}$ is composed of a dimer plus a loosely bonded atom ${ }^{48,49}$ and $\mathrm{Cr}_{4}$ of two dimers with strong intradimer but weak interdimer bonding. ${ }^{50}$ This dimerization effect controls the cluster growth up to $\mathrm{Cr}_{11}$, yielding similarities between the ground state photoabsorption spectra of dimers and small chromium clusters. ${ }^{50-52}$ The detection of $\mathrm{Cr}_{3}{ }^{+}$and $\mathrm{Cr}_{4}{ }^{+}$therefore suggests that the $\mathrm{Cr}_{2}$ dissociation process and surface migration of one atom is not disturbed by the presence of a further $\mathrm{Cr}$ atom or dimer in the droplet. 


\section{4 $\mathrm{Cr}_{2}$ excitation spectrum}

Now we turn to the $\mathrm{Cr}_{2} \mathrm{~A}^{1} \Sigma_{\mathrm{u}}{ }^{+} \leftarrow \mathrm{X}^{1} \Sigma_{\mathrm{g}}{ }^{+}$excitation band, in particular to the broad band stretching from 21500 to $22750 \mathrm{~cm}^{-1}$ that is present in the $\mathrm{Cr}^{+}$signal of the one-color REMPI scheme, shown as black curve in Fig. 2(a). We will now show that the signal of the broad band can be assigned to $\mathrm{Cr}_{2}$ molecules and arises from direct multiphoton ionization and subsequent dissociation to $\mathrm{Cr}$ and $\mathrm{Cr}^{+}$, an ionization path that does not include $\mathrm{Cr}_{2}$ predissociation. Outside the spectral regions of the $\mathrm{y}^{5} \mathrm{P}_{1,2,3}^{0} \leftarrow \mathrm{a}^{5} \mathrm{~S}_{2}$ transitions, i.e., without resonance enhancement, the ionization probability of both $\mathrm{Cr}$ atoms resulting from dissociation is estimated to be lower than a resonant ionization via vibronic levels of the $\mathrm{Cr}_{2}$ molecule before dissociation (see Fig. 1). Hence, we account resonant multiphoton ionization of $\mathrm{Cr}_{2}$ in combination with efficient dissociation to $\mathrm{Cr}$ and $\mathrm{Cr}^{+}$to be responsible for the observed signal.

It is instructive to compare the band obtained with one-color REMPI (Fig. 2(a)) to Fig. 2(b), which shows the $\mathrm{Cr}^{+}$signal of the two-laser $a^{7} S$ REMPI scheme where the dissociating laser is scanned. It is important to recall the following two points: (1) the $a^{7} S$ REMPI is obtained from resonant ionization of the center located ground state atoms that are produced via $\mathrm{Cr}_{2}$ predissociation. (2) The $a^{7} \mathrm{~S}$ REMPI is exclusively sensitive to $\mathrm{Cr}_{2}$ molecules and not to larger $\mathrm{Cr}_{n}$ clusters, as discussed in Section 4.2. Therefore, Fig. 2(b) represents the $\mathrm{Cr}_{2}$ excitation spectrum, which shows good overall agreement with the one-color REMPI band in Fig. 2(a). The extra features in the one-color REMPI spectrum in Fig. 2(a) with respect to the $a^{7} S$ REMPI spectrum in Fig. 2(b) indicate the presence of resonances in this ionization path. This interpretation is supported by monitoring the one-color REMPI $\mathrm{Cr}^{+}$ yield at the spectral positions marked with asterisks in Fig. 2(a) while increasing the evaporation oven temperature and comparing this signal to electron bombardment ion yield, as above. It is found that at all three spectral positions the $\mathrm{Cr}^{+}$ion signal can be assigned predominantly to $\mathrm{Cr}_{2}$ and not to larger $\mathrm{Cr}_{n}$ cluster.

The predissociation process, which is observed by the formation of ground state $\mathrm{a}^{7} \mathrm{~S}$ and metastable state $\mathrm{a}^{5} \mathrm{~S}$ atoms, has been reported for the $\mathrm{A}^{1} \Sigma_{\mathrm{u}}^{+} \leftarrow \mathrm{X}^{1} \Sigma_{\mathrm{g}}^{+}$excitation in literature. ${ }^{37,40,41,43}$ We note that the $\mathrm{Cr}_{2}$ might additionally be formed in higher multiplicities as it was observed for $\mathrm{Ag}_{2}$ in $\mathrm{He}_{\mathrm{N}} \cdot{ }^{53}$ However, currently we cannot identify other multiplicities. For the strongly bound $\mathrm{Cr}_{2}$ singlet ground state (binding energy = $\left.1.42 \mathrm{eV}\left(11450 \mathrm{~cm}^{-1}\right)^{38}\right)$, the majority of droplets are expected to survive the formation for a size distribution maximum of $\hat{N}=$ 6300 and an energy of $5 \mathrm{~cm}^{-1}$ dissipated per evaporated He atom. In gas phase, the $\mathrm{A}^{1} \Sigma_{\mathrm{u}}{ }^{+} \leftarrow \mathrm{X}^{1} \Sigma_{\mathrm{g}}{ }^{+} \mathrm{Cr}_{2}$ transition is observed at an energy of $21751 \mathrm{~cm}^{-1}(0-0$ band, $2.7 \mathrm{eV}) .{ }^{41,43,54} \mathrm{Cr}_{2}$ excitation spectra in other solid rare gas matrices yield usually shifted and broadened spectral features, but cannot provide a consistent picture about the magnitude of the shift. ${ }^{40,51,52,55,56}$

\section{Conclusions}

In conclusion, we have investigated the electronic $\mathrm{A}^{1} \Sigma_{\mathrm{u}}{ }^{+} \leftarrow \mathrm{X}^{1} \Sigma_{\mathrm{g}}{ }^{+}$ excitation of $\mathrm{Cr}_{2}$ molecules located inside $\mathrm{He}_{\mathrm{N}}$ with resonant multiphoton ionization spectroscopy, applying one- and two-laser schemes. The ionization spectra show, in addition to the droplet broadened molecular excitation structure, three pronounced peaks which we allocate to the $\mathrm{y}^{5} \mathrm{P}_{1,2,3}^{0} \leftarrow \mathrm{a}^{5} \mathrm{~S}_{2} \mathrm{Cr}$ atomic transitions. We conclude that the $\mathrm{Cr}_{2}$ molecule dissociates upon excitation ${ }^{41}$ into a solvated, ground state $\left(\mathrm{a}^{7} \mathrm{~S}_{3}\right)$ atom and a surface-located, metastable $\left(\mathrm{a}^{5} \mathrm{~S}_{2}\right)$ atom. The latter is ionized by resonance-enhanced multiphoton ionization. The conclusion is based on (a) the $\mathrm{y}^{5} \mathrm{P}_{1,2,3}^{0} \leftarrow$ $\mathrm{a}^{5} \mathrm{~S}_{2}$ transition line shape $\left(50 \mathrm{~cm}^{-1}\right.$ width and a $5 \mathrm{~cm}^{-1}$ blueshift of the onset with respect to the bare atom lines), (b) a two laser experiment with REMPI detection of the produced $\mathrm{a}^{7} \mathrm{~S}_{3}$ atoms, and (c) theoretical simulations of the $\mathrm{a}^{5} \mathrm{~S}_{2}$ atom location. ${ }^{45}$ Surprisingly, we detect these three $\mathrm{y}^{5} \mathrm{P}_{1,2,3}^{0} \leftarrow \mathrm{a}^{5} \mathrm{~S}_{2}$ atom peaks not only at the $\mathrm{Cr}^{+}$ion mass, but also at $\mathrm{Cr}_{2,3,4}{ }^{+}$masses. $\mathrm{Cr}_{2}{ }^{+}$detection demonstrates that upon photoionization, a fraction of the surface atoms migrates back inside the droplet to recombine with their ground state counterpart. The $\mathrm{Cr}_{3,4}{ }^{+}$detection indicates that this pairwise dissociation and surface migration process is not disturbed by the presence of additional $\mathrm{Cr}$ atoms, a fact which we attribute to the strong dimerization effect in small Cr clusters. ${ }^{50}$

The elucidated mechanisms open a possibility for photoinduced chemistry mediated by $\mathrm{He}_{\mathrm{N}}$. Chemical reactions in $\mathrm{He}_{\mathrm{N}}$ doped with both surface located (e.g., alkali-metal or alkaline earth metal atoms) and solvated species could be triggered by photoexcitation of the latter to a surface located state. The bond formation can then be followed, e.g., with timeresolved femtosecond spectroscopy.

\section{Acknowledgements}

The authors thank Friedrich Lindebner for experimental assistance as well as Martin Ratschek and Johann V. Pototschnig for computational support and Florian Lackner for careful reading. The research was supported by the Austrian Science Fund (FWF) under grant number P22962-N20 and by the European Commission and the Styrian Government within the ERDF program.

\section{References}

1 C. Callegari and W. E. Ernst, Helium Droplets as Nanocryostats for Molecular Spectroscopy - from the Vacuum Ultraviolet to the Microwave Regime, Handbook of High-Resolution Spectroscopy, John Wiley \& Sons, Chinchester, 2011.

2 J. M. Merritt, J. Kupper and R. E. Miller, Phys. Chem. Chem. Phys., 2005, 7, 67-78.

3 J. M. Merritt, S. Rudić and R. E. Miller, J. Chem. Phys., 2006, 124, 084301.

4 S. Rudić, J. M. Merritt and R. E. Miller, J. Chem. Phys., 2006, 124, 104305.

5 J. Küpper and J. M. Merritt, Int. Rev. Phys. Chem., 2007, 26, 249-287.

6 A. M. Morrison, J. Agarwal, H. F. Schaefer and G. E. Douberly, J. Phys. Chem. A, 2012, 116, 5299-5304.

7 K. von Haeften, A. Metzelthin, S. Rudolph, V. Staemmler and M. Havenith, Phys. Rev. Lett., 2005, 95, 215301. 
8 D. Stolyarov, E. Polyakova and C. Wittig, J. Phys. Chem. A, 2004, 108, 9841-9846.

9 A. Braun and M. Drabbels, J. Chem. Phys., 2007, 127, 114305.

10 K. Nauta and R. E. Miller, Science, 1999, 283, 1895-1897.

11 K. Nauta and R. E. Miller, Science, 2000, 287, 293-295.

12 G. E. Douberly and R. E. Miller, J. Phys. Chem. A, 2007, 111, 7292-7302.

13 G. E. Douberly, J. M. Merritt and R. E. Miller, Phys. Chem. Chem. Phys., 2005, 7, 463-468.

14 T. Liang, S. D. Flynn, A. M. Morrison and G. E. Douberly, J. Phys. Chem. A, 2011, 115, 7437-7447.

15 F. Ancilotto, P. B. Lerner and M. W. Cole, J. Low Temp. Phys., 1995, 101, 1123-1146.

16 F. Federmann, K. Hoffmann, N. Quaas and J. D. Close, Phys. Rev. Lett., 1999, 83, 2548-2551.

17 N. B. Brauer, S. Smolarek, E. Loginov, D. Mateo, A. Hernando, M. Pi, M. Barranco, W. J. Buma and M. Drabbels, Phys. Rev. Lett., 2013, 111, 153002.

18 D. Mateo, A. Hernando, M. Barranco, E. Loginov, M. Drabbels and M. Pi, Phys. Chem. Chem. Phys., 2013, 15, 18388-18400.

19 F. Lindebner, A. Kautsch, M. Koch and W. E. Ernst, Int. J. Mass Spectrom., 2014, 365-366, 255-259.

20 F. Cargnoni and M. Mella, J. Phys. Chem. A, 2011, 115, 7141-7152.

21 A. Kautsch, M. Hasewend, M. Koch and W. E. Ernst, Phys. Rev. A: At., Mol., Opt. Phys., 2012, 86, 033428.

22 A. Kautsch, M. Koch and W. E. Ernst, J. Phys. Chem. A, 2013, 117, 9621-9625.

23 M. Koch, A. Kautsch, F. Lackner and W. E. Ernst, J. Phys. Chem. A, 2014, 118, 8373-8379.

24 A. Braun and M. Drabbels, Phys. Rev. Lett., 2004, 93, 253401.

25 A. Braun and M. Drabbels, J. Chem. Phys., 2007, 127, 114303.

26 E. Polyakova, D. Stolyarov and C. Wittig, J. Chem. Phys., 2006, 124, 214308.

27 J. Poms, A. W. Hauser and W. E. Ernst, Phys. Chem. Chem. Phys., 2012, 14, 15158-15165.

28 A. Masson, M. Briant, A. Hernando, N. Halberstadt, J.-M. Mestdagh and M.-A. Gaveau, J. Chem. Phys., 2012, 137, 184310.

29 E. Lugovoj, J. P. Toennies and A. Vilesov, J. Chem. Phys., 2000, 112, 8217-8220.

30 G. E. Douberly, P. L. Stiles, R. E. Miller, R. Schmied and K. K. Lehmann, J. Phys. Chem. A, 2010, 114, 3391-3402.

31 L. An der Lan, P. Bartl, C. Leidlmair, R. Jochum, S. Denifl, O. Echt and P. Scheier, Chem. - Eur. J., 2012, 18, 4411-4418.

32 M. Theisen, F. Lackner and W. E. Ernst, Phys. Chem. Chem. Phys., 2010, 12, 14861-14863.

33 M. Theisen, F. Lackner, G. Krois and W. E. Ernst, J. Phys. Chem. Lett., 2011, 2, 2778-2782.
34 X. Zhang and M. Drabbels, J. Chem. Phys., 2012, 137, 051102.

35 M. Koch, J. Lanzersdorfer, C. Callegari, J. S. Muenter and W. E. Ernst, J. Phys. Chem. A, 2009, 113, 13347-13356.

36 M. Ratschek, M. Koch and W. E. Ernst, J. Chem. Phys., 2012, 136, 104201.

37 K. Andersson, Chem. Phys. Lett., 1995, 237, 212-221.

38 C.-X. Su, D. A. Hales and P. Armentrout, Chem. Phys. Lett., 1993, 201, 199-204.

39 A. Kramida, Y. u. Ralchenko, J. Reader and NIST ASD Team, NIST Atomic Spectra Database (ver. 5.0), National Institute of Standards and Technology, Gaithersburg, MD, 2012, online. Available: http://physics.nist.gov/asd, 2013, may 16.

40 M. J. Pellin and D. M. Gruen, J. Chem. Phys., 1983, 79, 5887-5893.

41 S. J. Riley, E. K. Parks, L. G. Pobo and S. Wexler, J. Chem. Phys., 1983, 79, 2577-2582.

42 J. Higgins, C. Callegari, J. Reho, F. Stienkemeier, W. E. Ernst, K. K. Lehmann, M. Gutowski and G. Scoles, Science, 1996, 273, 629-631.

43 V. Bondybey and J. English, Chem. Phys. Lett., 1983, 94, 443-447.

44 J. V. Pototschnig, M. Ratschek, A. W. Hauser and W. E. Ernst, Phys. Chem. Chem. Phys., 2014, 16, 9469-9478.

45 M. Ratschek, J. V. Pototschnig, A. W. Hauser and W. E. Ernst, J. Phys. Chem. A, 2014, 118, 6622-6631.

46 G. Auböck, J. Nagl, C. Callegari and W. E. Ernst, Phys. Rev. Lett., 2008, 101, 035301.

47 A. Przystawik, S. Göde, T. Döppner, J. Tiggesbäumker and K.-H. Meiwes-Broer, Phys. Rev. A: At., Mol., Opt. Phys., 2008, 78, 021202.

48 H. Cheng and L.-S. Wang, Phys. Rev. Lett., 1996, 77, 51-54.

49 L.-S. Wang, H. Wu and H. Cheng, Phys. Rev. B: Condens. Matter Mater. Phys., 1997, 55, 12884-12887.

50 J. I. Martínez and J. A. Alonso, Phys. Rev. B: Condens. Matter Mater. Phys., 2007, 76, 205409.

51 L. Fang, B. Davis, H. Lu and J. R. Lombardi, J. Phys. Chem. A, 2001, 105, 9375-9378.

52 J. Derouault and M. Dalibart, Z. Phys. D: At., Mol. Clusters, 1991, 19, 211-214.

53 A. Przystawik, P. Radcliffe, S. Göde, K. H. Meiwes-Broer and J. Tiggesbäumker, J. Phys. B: At., Mol. Opt. Phys., 2006, 39, S1183-S1189.

54 D. L. Michalopoulos, M. E. Geusic, S. G. Hansen, D. E. Powers and R. E. Smalley, J. Phys. Chem., 1982, 86, 3914-3916.

55 E. P. Kündig, M. Moskovits and G. A. Ozin, Nature, 1975, 254, 503-504.

56 M. Vala, R. Pyzalski, J. Shakhsemampour, M. Eyring, J. Pyka, T. Tipton and J. C. Rivoal, J. Chem. Phys., 1987, 86, 5951-5957. 